\title{
Central Antitussive Effect of Codeine in the Anesthetized RABBIT
}

\author{
M. Simera, I. Poliacek, J. Jakus \\ Institute of Medical Biophysics, Comenius University, Martin, Slovakia
}

\begin{abstract}
Background: Codeine represents a commonly used drug to suppress cough. Central antitussive effect of codeine has been confirmed in a number of animal studies. However, available data related to antitussive activity of codeine in rabbits are very limited.

Objective: We investigated the effects of codeine on cough, single expiratory responses (expiration-like reflex) induced by mechanical tracheo-bronchial stimulation, and on the sneeze reflex in the anesthetized rabbit.

Material and methods: Twenty pentobarbitone anesthetized spontaneously breathing rabbits were used for the study. Increasing doses of codeine (codeinum dihydrogenphosphate, Interpharm) were injected intravenously (iv); $0,0.15,0.76$, and $3.78 \mathrm{mg} / \mathrm{kg}$ of codeine dissolved in saline, $0.25 \mathrm{ml} / \mathrm{kg}$ ) or intracerebroventricularly (icv); $0,0.015,0.076$, and $0.378 \mathrm{mg} / \mathrm{kg}$ of codeine dissolved in artificial cerebrospinal fluid, $0.033 \mathrm{ml} / \mathrm{kg}$.

Results: Both iv and icv injections of codeine led to a dose-dependent reduction of coughing provoked by tracheo-bronchial stimulation; however, the doses differed substantially. The effective cumulative dose for a $50 \%$ reduction in the number of coughs was 3.9 and $0.11 \mathrm{mg} / \mathrm{kg}$ after iv and icv administration of codeine, respectively; representing about 35 -fold higher efficacy of the icv route. The numbers of expiration-like responses and sneeze reflex responses remained unchanged.

Conclusions: The study confirmed the central antitussive effect of codeine, but showed a low sensitivity of sneeze and expiration reflex to codeine. We validated the experimental model of an anesthetized rabbit for studies on central antitussive action.
\end{abstract}

Key words: antitussive, tracheo-bronchial cough, sneeze, expiration, airway defense

\section{INTRODUCTION}

Antitussive drugs, such as codeine and dextromethorphan, are among the most commonly prescribed medicines in the world. Codeine acts antitussively within the brain stem, where the basic neuronal circuitry responsible for coughing is located [1-3]. Central action of codeine is accepted, since the drug is more effective when administered centrally, either via the vertebral artery or intracerebroventricularly (icv) into the $4^{\text {th }}$ brain ventricle, compared with an intravenous (iv) route [4].

Codeine is considered to be primarily the $\mu$-opioid receptor agonist $[5,6]$. However, for central antitussives, including codeine, also other than $\mu$-opioid receptor mechanisms have been proposed [5, 7-9].

Codeine reduces the number of coughs provoked by tracheo-bronchial stimulation; decreasing the expiratory (E) component of cough efforts, with a much lower effect on the inspiratory (I) one, cough timing, and parameters of respiration [10,11]. However, a complete analysis of the effect of codeine on cough motor pattern has never been performed in the rabbit [12].

Previous studies have shown the effective antitussive dose of codeine in experimentally produced cough in anesthetized rabbits was $100 \mathrm{mg} / \mathrm{kg}$ for oral and $1-10 \mathrm{mg} / \mathrm{kg}$ for iv administration $[13,14]$. However, none of the studies have attempted to analyze and determine $\mathrm{ED}_{50}$ (effective dose for $50 \%$ reduction of coughing) providing the base for comparison of antitussive efficacy upon different routes of codeine administration and for the determination of its central or peripheral action $[4,11]$.

In the present study we investigated the hypothesis that in the rabbit the codeine would centrally suppress tracheo-bronchial cough at a lower dose than that required for iv administration.

\section{Material And Methods}

\section{General Procedures and Stimulation}

All procedures were performed in accordance with the laws, rules, and regulations of Slovakian Government and EC; the Ethics Committee of Jessenius Faculty of Medicine in Martin approved the protocols.

Experiments were performed in 20 rabbits (New Zeland white, line P91; $3.65 \pm 0.15 \mathrm{~kg}$ ) of either sex, pre-medicated with the diazepam (Apaurin, KRKA, Croatia; $5 \mathrm{mg} / \mathrm{kg}, \mathrm{im}$ ) and anesthetized with sodium pentobarbital (Biowet, Pulawy, Poland; $35 \mathrm{mg} / \mathrm{kg}$, ip). Supplementary anesthetic doses were administered (1$3 \mathrm{mg} / \mathrm{kg}$, iv) as needed. Atropine (Biotika; 0.15 $\mathrm{mg} / \mathrm{kg}$, iv) was given at the beginning of the experiment to reduce secretions. The trachea, femoral artery and vein were canulated. The animals were allowed to breathe spontaneously a gas mixture of $30-60 \%$ oxygen, balanced by nitrogen. Arterial blood pressure (BP), end-tidal $\mathrm{CO}_{2}$ concentration $\left(\mathrm{ETCO}_{2}\right)$, respirato- 
ry rate (RR), and body temperature were monitored continuously. Body temperature was maintained at $39.0 \pm 0.5^{\circ} \mathrm{C}$. Periodically, the samples of arterial blood were removed for blood gases and $\mathrm{pH}$ analysis.

Bipolar fine wire hook electrodes were placed in the crural diaphragm (DIA) and bilaterally in the transversal abdominal, or the external oblique abdominal muscles (ABD) for electromyogram (EMG) recordings. A soft balloon was inserted into the esophagus for a measurement of the intrathoracic pressure changes (esophageal pressure - EP). Foramen magnum with the occipital bone was carefully exposed, a thin polyethylene catheter was inserted throughout and fixed in dura mater for central injections of codeine. The tip of the catheter was positioned about $2 \mathrm{~mm}$ rostral to the obex (the most caudal point of the area postrema) in the $4^{\text {th }}$ brain ventricle. The position and patency of the catheter were tested post-mortem.

Tracheo-bronchial cough was induced by a mechanical stimulation of the trachea and the carina areas with a nylon loop attached to a soft catheter. This tool was inserted into the trachea and moved fore and back toward carina 4 times during one stimulation trial. Sneeze was induced by mechanical stimulation (4 touches) of the nasal septum with a soft nylon fiber ( $\varnothing 0.3 \mathrm{~mm}$ ). Cough or sneeze were defined by a large augmenting burst of diaphragm (DIA) EMG activity immediately followed (and partially overlapped) by a burst of $\mathrm{E}$ abdominal (ABD) EMG activity corresponding to the related I-E wave of EP. Stimulation of tracheo-bronchial airways also resulted in single expiratory responses (ER-like response) independent of, and separated from, the previous inspiration. These expiratory responses were analyzed separately from coughing.

Codeinum dihydrogenphosphate (Interpharm, Bratislava, Slovakia) was dissolved in saline for iv (via femoral vein; $0.25 \mathrm{ml}$ of solution $/ \mathrm{kg}$ ) and in the artificial cerebrospinal fluid (aCSF) for icv injection ( via the catheter fixed in the foramen magnum; $0.033 \mathrm{ml}$ of solution $/ \mathrm{kg}$ ). Increasing doses of codeine were injected iv (pure saline followed by $0.2,0.8$, and $4.0 \mathrm{mg} / \mathrm{kg}$ ), representing cumulative doses of $0,0.15,0.76$, and $3.78 \mathrm{mg} / \mathrm{kg}$ or icv (pure aCSF followed by $0.02,0.08$, and $0.4 \mathrm{mg} / \mathrm{kg}$ ), representing cumulative doses of 0 , $0.015,0.076$, and $0.378 \mathrm{mg} / \mathrm{kg}$ of codeine). Stimulation of tracheo-bronchial airways and the nasal mucosa were performed at 1 min intervals; two stimulation trials before the first (saline or aCSF) and after each injection. During the icv injection protocol, additional stimulations were performed more than $30 \mathrm{~min}$ after the last injection ('recovery'). The experiment was terminated by an iv overdose of pentobarbitone, followed by a saturated solution of $\mathrm{KCl}$.

\section{Data Processing AND THEIR ANALYsis}

All EMGs were amplified, filtered (300-3000 Hz; Iso DAM8, WPI), digitalized (12-bit multi-function plugin ISA card, Dataq Instruments, OH, USA, sampling frequency of $20.000 \mathrm{~Hz}$ ), and recorded (WinDaq, Dataq Instruments - Akron, OH, USA) along with the waveforms of BP and EP.

The number of cough efforts and single expiratory responses induced during the mechanical probing of the lower airways (mean number of coughs and single expiratory efforts - EN per 4 penetrations and touches of carina) and the number of sneeze efforts in response to stimulation of the nasal septum (mean number of sneezes - SN per 4 touches of nasal mucosa) were analyzed in each sequence of trials. We also performed a complex spatiotemporal analysis of studied responses (cough, sneeze, single expiratory responses) including the duration of DIA, ABD activity, augmenting and decrementing part of these activities, overlapping of them, the duration of quiescent period between coughs or sneezes (the intervals from the end of ABD activity to the beginning of the next DIA activity such as next cough/sneeze or eupneic inspiration). Differences in amplitudes of DIA and ABD moving averages and of $\mathrm{I}$ and $\mathrm{E}$ components of the esophageal pressure recording between those obtained in response to saline or aCSF and codeine injections were measured.

The results are expressed as means \pm SE. For statistical analysis $t$-test, Mann-Whitney $\mathrm{U}$ test, and repeated measures ANOVA with the Student-NewmanKeuls post-hoc test were applied as appropriate. The differences of variables were considered significant at $\mathrm{P}<0.05$.

\section{RESULTS}

Mechanical tracheal-bronchial stimulation produced coughing and single expiratory responses (Fig. 1), while nasal stimuli resulted in vigorous sneezing in our animals (Fig. 2). Spatiotemporal analysis of the cough reflex during sequential stimulation (up to 6 stimulation sequences, each with 2 tracheo-bronchial stimulation trials) showed no significant differences. No sig-

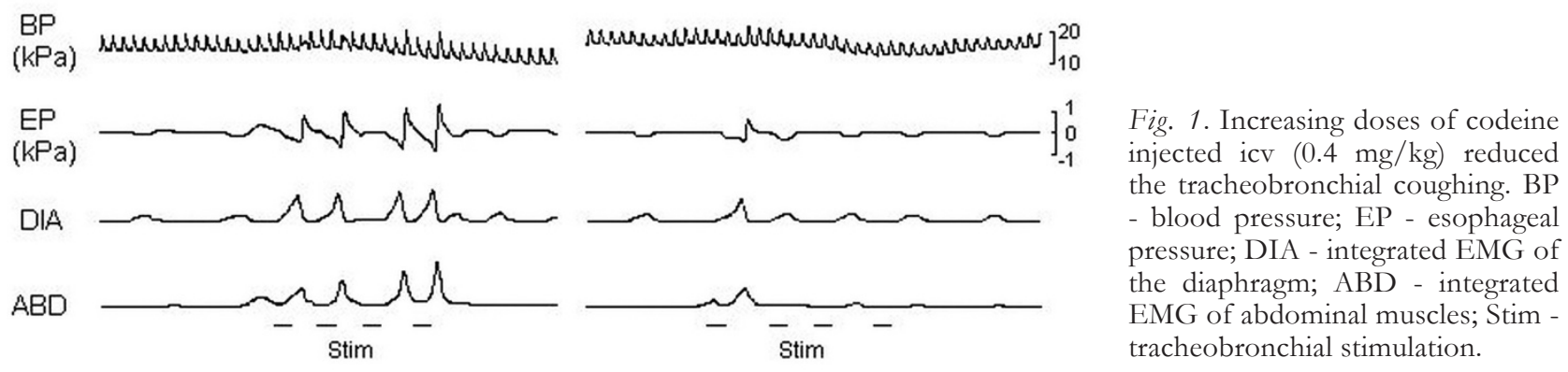


Control

$\mathrm{BP}$ (KPa)

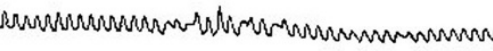

(kPa)

DIA

$\mathrm{ABD}$

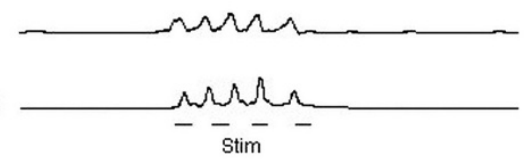

Codeine

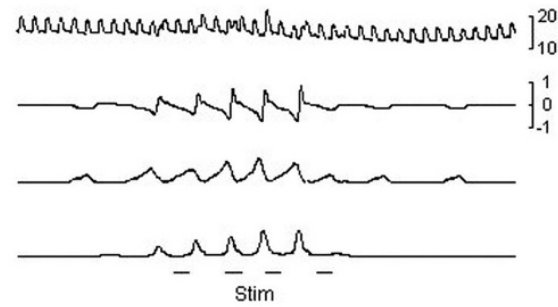

Fig. 2. Increasing doses of codeine injected icv $(0.4 \mathrm{mg} / \mathrm{kg})$ did not affect sneezing. BP - blood pressure; EP - esophageal pressure; DIA integrated EMG of the diaphragm; ABD - integrated EMG of abdominal muscles; Stim - nasal stimulation.

Table 1. Parameters of coughing after iv and icv application of increasing doses of codeinum dihydrogenphosphate (mg/kg).

\begin{tabular}{|c|c|c|c|c|c|}
\hline IV & \multicolumn{5}{|c|}{9 rabbits -7 males +2 females $(3.71 \pm 0.15 \mathrm{~kg})$} \\
\hline dose & $\mathrm{CN}$ & $\% \operatorname{dif}$ DIA & $\% \operatorname{dif} \mathrm{ABD}$ & $\%$ dif EP I & \%dif EP E \\
\hline saline & $2.6 \pm 0.7$ & 100 & 100 & 100 & 100 \\
\hline 0.2 & $1.9 \pm 0.5$ & $80 \pm 9$ & $73 \pm 15$ & $94 \pm 8$ & $66 \pm 13$ \\
\hline 0.8 & $1.9 \pm 0.5$ & $97 \pm 13$ & $83 \pm 12$ & $90 \pm 13$ & $81 \pm 17$ \\
\hline $\begin{array}{c}4 \\
\text { ANOVA }\end{array}$ & $\begin{array}{l}1.2 \pm 0.4^{* *} \\
\mathrm{P}<0.05\end{array}$ & $\begin{array}{c}63 \pm 14 \\
\mathrm{P}>0.05\end{array}$ & $\begin{array}{l}51 \pm 12^{*+} \\
\mathrm{P}<0.05\end{array}$ & $\begin{array}{l}68 \pm 12 \\
P>0.05\end{array}$ & $\begin{array}{l}52 \pm 13^{++} \\
\mathrm{P}>0.05\end{array}$ \\
\hline ICV & \multicolumn{5}{|c|}{9 rabbits -5 males +4 females $(3.94 \pm 0.15 \mathrm{~kg})$} \\
\hline dose & $\mathrm{CN}$ & $\% \operatorname{dif} \mathrm{DIA}$ & $\%$ dif $\mathrm{ABD}$ & $\%$ dif EP I & \%dif EP E \\
\hline aCSF & $2.3 \pm 0.6$ & 100 & 100 & 100 & 100 \\
\hline 0.02 & $1.5 \pm 0.3$ & $84 \pm 18$ & $102 \pm 27$ & $97 \pm 21$ & $91 \pm 17$ \\
\hline 0.08 & $1.0 \pm 0.2^{*++}$ & $79 \pm 14$ & $85 \pm 19$ & $102 \pm 16$ & $86 \pm 19$ \\
\hline 0.4 & $0.8 \pm 0.2^{* *++}$ & $64 \pm 17$ & $50 \pm 19 *+\# \&$ & $101 \pm 26$ & $50 \pm 16^{*}$ \\
\hline recovery & $2.5 \pm 0.4$ & $87 \pm 8$ & $117 \pm 10$ & $134 \pm 18$ & $89 \pm 10$ \\
\hline ANOVA & $\mathrm{P}=0.001$ & $\mathrm{P}>0.05$ & $\mathrm{P}<0.05$ & $\mathrm{P}>0.05$ & $\mathrm{P}<0.05$ \\
\hline
\end{tabular}

$\mathrm{CN}$ - cough number, DIA - diaphragmatic EMG activity, ABD - abdominal EMG ativity, EP - esophageal pressure, I \& E inspiratory \& expiratory components of esophageal pressure trace.

$* \mathrm{P}<0.05, * * \mathrm{P}<0.01$ compared with control (saline or aCSF);

$+\mathrm{P}<0.05,{ }^{++} \mathrm{P}<0.01$ compared with control stimulations (5 $5^{\text {th }}$ series of stimulation trials without injection);

\# $\mathrm{P}<0.05$ - codeine $0.4 \mathrm{mg} / \mathrm{kg}$ compared with recovery;

$\& \mathrm{P}<0.05$ - codeine $0.02 \mathrm{mg} / \mathrm{kg}$ compared with codeine $0.4 \mathrm{mg} / \mathrm{kg}$.

nificant differences were also detected in the parameters of induced responses before and after injection (saline for iv and aCSF for icv protocols).

Increasing doses of codeine, injected either iv or icv, reduced the number of coughs, the cough expiratory effort expressed in the esophageal pressure recording, and ABD EMG moving average amplitudes (Table 1). The number of coughs and the difference in cough ABD EMG amplitude following the highest dose of codeine, in both icv and iv protocols, were significantly lower than those at the $5^{\text {th }}$ sequence of repetitive control cough stimulations (Table 1). A reduced number of coughs was associated with a tendency for a prolongation of the period of relative motor quiescence during the cough expiratory period (in case of repetitive coughing representing the intercough interval within the cough trial) and of the total cough cycle duration. We found no differences in the expression of $\mathrm{EN}$ or $\mathrm{SN}$, their intensities, or timing of single expiratory responses and sneezes during both icv and iv codeine protocols.

Furthermore, we found a linear relationship between cough number reduction and the logarithm of the cumulative codeine dose $(r=0.95$ and $r=0.98$ for iv and icv protocols, respectively), with the slopes significantly different from zero $(\mathrm{P}<0.05)$. The effective doses of codeine for $50 \%$ reduction in the cough number $\left(\mathrm{ED}_{50}\right)$, extrapolated from the regression analysis, were 3.9 and $0.11 \mathrm{mg} / \mathrm{kg}$ for iv and icv administration. The ivED $\mathrm{E}_{50} / \mathrm{icvED}_{50}$ ratio was $\sim 35$. We found no appreciable differences in RR and BP during our protocols, with the exception of a slightly reduced mean BP (from $10.5 \pm 1.0$ to $9.5 \pm 1,0$; $\mathrm{P}<0.01$ ) following the highest iv codeine dose.

\section{DisCusSION}

The major finding of this study was that codeine suppressed the cough reflex in the anesthetized rabbit, and that intracerebroventricular route of its administration was much more efficient to this end. Thus, the results confirmed the central antitussive effect of codeine in response to mechanically-induced tracheobronchial cough. In contrast, sensitivity of the sneeze and expiration-like reflexes to codeine was low. In addition, we validated the experimental model of an 
anesthetized rabbit for studies on central antitussives.

In this study we performed sequential tracheobronchial stimulation for up to 13 times and demonstrated a stable cough response during these control, non-injection trials. The stability of coughing allowed us to compare coughing in codeine-treated and -untreated animals. The number of coughs and $\mathrm{E}$ efforts during coughing was reduced in codeine-treated rabbits (at the highest dose of codeine) compared with the $5^{\text {th }}$ series $\left(5^{\text {th }}\right.$ pair) of stimulations in the untreated rabbits, and also when compared with coughing after the vehicle injection alone in codeine-treated animals. We further showed that the dose of codeine necessary for a $50 \%$ reduction in the number of coughs $\left(\mathrm{ED}_{50}\right)$ was many-fold smaller in case of icv than iv codeine administration. That points to a central site of antitussive action of codeine in the anesthetized rabbit as it has also been reported by others $[11,15]$. Our results showing suppression of cough by codeine and the analysis of temporary cough characteristics that is similar to previous data in cats [12] support the notion that central antitussive drugs act by the inhibition of specific components of the cough neuronal control and do not generally suppress all aspects of its motor task $[10,11]$.

Codeine is a $\mu$-opioid receptor agonist. These receptors are abundantly expressed in the brainstem areas involved in cough production, such as the ambiguus, solitary tract, medial parabrachial, and raphe nuclei, and possibly the periaqueductal gray matter [5]. However, the antitussive effects of different $\mu$-opioid receptor agonists greatly vary, as also does the efficacy of codeine in cough suppression in individual animal species [16]. The antitussive effects of codeine are only little blocked by naloxone, a non-specific opioid receptor antagonist, mainly in cats [5].

Thus, the exact structures and neuronal populations that are affected by central antitussives to reduce cough are largely unknown. Application of different antitussive agents (DAMGO and baclofen) within the caudal aspect of the solitary tract nucleus in the rabbit induces decreases in the number of coughs, peak abdominal activity, and in the duration of the cough respiratory cycle; the latter being augmented due to cough-related prolongation of both I and E components of the cycle. In the present study we found no significant changes in the total cough cycle duration or $\mathrm{I}$ and $\mathrm{E}$ cough phase durations during our codeine protocols. Those findings are in line with the lack of changes in temporal characteristics of cough being reported after codeine microinjections into the caudal part of the ventral respiratory group in cats [12]. This study also confirmed the lack of a suppressive effect of codeine on sneeze and 'expiration-like' single reflex expiratory responses after codeine, which accords with other studies [15, 17] and indicates different central control mechanisms for cough and the other two reflex responses.

A limitation of this and other studies is a mechanical probing in the tracheo-bronchial region to induce cough. Pathological cough seems to be more related to chemical stimuli, involving peripheral and central plasticity and up-regulation of cough at multiple levels of the cough neural pathway $[10,11,18]$. Cough is a complex phenomenon affected by a number of systemic and regulatory malfunctions, and non-specific environmental factors [18-20].

In this study we did not detect changes in respiratory rate or blood pressure after the application of increasing doses of codeine. That indicates a limited respiratory effect of central antitussives at a dose which is capable of suppressing the cough reflex, which has also been found in other reports [11]. However, we detected a weak, but statistically significant, decrease in BP after iv application of the highest dose of codeine. Other authors have previously shown that codeine causes a combination of pulmonary vasoconstriction and systemic vasodilation in the anesthetized dog [21], and opioids, in higher doses, generally reduce peripheral and aortic systolic, mean, and end-systolic pressures [22]. In clinical use of codeine as an antitussive agent these possible untoward effects should thus be taken into consideration.

Acknowledgements: We gratefully acknowledge the technical assistance of Assoc. Prof. Helena Barani, Mgr. Nadezda Visnovcova, Eva Frolova, Ing. Peter Machac, Roman Kubizna, Mgr. Ivana Lamosova as well as inspiring revision of the manuscript by Prof. Mieczyslaw Pokorski. This study was cofinanced form VEGA 1/0038/09 and EC sources - European Regional Development Fund (CECR).

Conflicts of interests: The authors declare no conflicts of interest in relation to this article.

\section{REFERENCES}

1. Shannon R, Baekey DM, Morris KF, Nuding SC, Segers LS, Lindsey BG. Production of reflex cough by brainstem respiratory networks. Pulm Pharmacol Ther 2004; 17(6): 369-76.

2. Bolser DC, Poliacek I, Jakus J, Fuller DD, Davenport PW. Neurogenesis of cough, other airway defensive behaviors and breathing: a holarchical system? Respir Physiol Neurobiol 2006; 152: 255-65.

3. Jakus J, Poliacek I, Halasova E, Murin P, Knocikova J, Tomori Z, Bolser DC. Brainstem circuitry of trachealbronchial cough: c-fos study in anesthetized cats. Respir Physiol Neurobiol 2008; 160(3): 289-300.

4. Bolser DC, Degennaro FC, O'Reilly S, Hey JA, Chapman RW. Pharmacological studies of alergic cough in the guinea pig. Eur J Pharmacol 1995; 277(2-3): 159-64.

5. Takahama K, Shirasaki T. Central and peripheral mechanisms of narcotic antitussives: codeine-sensitive and -resistant coughs. Cough 2007; 3: 8 .

6. Kotzer CJ, Hay DW, Dondio G, Giardina G, Petrillo P, Underwood DC. The antitussive activity of delta-opioid receptor stimulation in guinea pigs. J Pharmacol Exp Ther 2000; 292(2): 803-9.

7. Yamakura T, Sakimura K, Shimoji K. Direct inhibition of the N-methyl-D-aspartate receptor channel by high concentrations of opioids. Anesthesiology 1999; 91(4): 1053 63.

8. Nosalova G. Actions of drugs affecting the cough reflex. Bratisl Lek Listy 1998; 99(10): 531-5 (Article in Slovak).

9. Kamei J. Role of opioidergic and serotonergic mechanisms in cough and antitussives. Pulm Pharmacol 1996; 9(5-6): 349-56.

10. Bolser DC, Davenport PW. Functional organization of the central cough generation mechanism. Pulm Pharmacol Ther 2002; 15(3): 221-5.

11. Bolser DC, Hey JA, Chapman RW. Influence of central antitussive drugs on the cough motor pattern. J Appl Physiol 1999; 86: 1017-24. 
12. Poliacek I, Wang C, Corrie LW, Rose MJ, Bolser DC. Microinjection of codeine into the region of the caudal ventral respiratory column suppresses cough in anesthetized cats. J Appl Physiol 2010; 108(4): 858-65.

13. Graham JDP. Evaluation of isoaminile citrate as an antitussive. J Clin Pharmacol 1962; 2: 43-9.

14. Furakawa F, Okabe M. The antitussive action of dextromethorphan hydrobromide. Igaku Kenkya 1958; 28: 1643-7.

15. Korpas J, Tomori Z. Cough and Other Respiratory Reflexes. Karger, New York 1979.

16. Eddy NB, Friebel H, Hahn KJ, Halbach H. Codeine and its alternates for pain and cough relief. The antitussive action of codeine-mechanisms, methodology and evaluation. Bull World Health Organ 1969; 40(3): 425-54.

17. Poliacek I, Rose MJ, Corrie LW, Wang C, Jakus J, Barani H, Stransky A, Polacek H, Halasova E, Bolser DC. Short reflex expirations (expiration reflexes) induced by mechanical stimulation of the trachea in anesthetized cats. Cough 2008; 4: 1.

18. Plevkova J, Antosiewicz J, Varechova S, Poliacek I, Jakus J, Tatar M, Pokorski M. Convergence of nasal and tracheal neural pathways in modulating the cough response in guinea pigs. J Physiol Pharmacol 2009; 60(2): 89-93.

19. Jakusova V. Ultraviolet Radiation and Mobile Communication. In: Physical Properties, Biological Effects and Health Protection. SAMOSATO, Bratislava, 2009; ISBN: 978-80-89464-00-5 (in Slovak).
20. Brozmanova M, Javorkova N, Hajtmanova E, Zamecnik L, Javorka M, Hanacek J, Tatar M. Influence of chest gamma-irradiation on cough response in awake guinea pigs. J Physiol Pharmacol 2007; 58 Suppl 5: 67-74.

21. Bianchi A, Aviado DM. Antitussive drugs. I. Cardiopulmonary effects of codeine. Arch Int Pharmacodyn Ther 1975; 216(2): 208-15.

22. Afshari R, Maxwell SR, Bateman DN. Hemodynamic effects of methadone and dihydrocodeine in overdose. Clin Toxicol (Phila) 2007; 45(7): 763-72.

Address for correspondence:

Michal Simera

Institute of Medical Biophysics

Jessenius Faculty of Medicine

Comenius University

Mala Hora 4

037 54, Martin

Slovakia

Phone: +421 434221422

Fax: +421434222260

E-mail: simera@jfmed.uniba.sk 